\title{
A IMPORTÂNCIA DA TECNOLOGIA NA EDUCAÇÃO DURANTE O PERÍODO DE PANDEMIA DA COVID-19
}

\section{THE IMPORTANCE OF TECHNOLOGY IN EDUCATION DURING THE COVID-19 PANDEMIC PERIOD}

\author{
Daniel Sadala - dsadala.86@gmail.com \\ Faculdade de Tecnologia de Taquaritinga - Taquaritinga - São Paulo - Brasil \\ Daniela Gibertoni - daniela.gibertoni@fatectq.edu.br \\ Faculdade de Tecnologia de Taquaritinga - Taquaritinga - São Paulo - Brasil
}

DOI: 10.31510/infa.v18i1.1150

Data de submissão: 17/04/2021

Data do aceite: 09/07/2021

Data da publicação: 30/07/2021

\section{RESUMO}

Em dezembro de 2019, a China notificou a Organização Mundial da Saúde (OMS) sobre a epidemia de um vírus similar a uma pneumonia viral na província de Wuhan. Em março de 2020, foi decretado estado de pandemia em todos os cantos do mundo em decorrência da alta infectividade do novo coronavírus, a fim de atenuar sua grande contaminação, autoridades do mundo inteiro, inclusive no Brasil, optaram por adotarem manobras que visassem a minimização de contágio, uma dessas manobras foi o isolamento social, tornando rotinas tradicionais um pouco mais flexíveis, como o caso do ensino a distância. Por meio de um levantamento bibliográfico, buscou-se averiguar os principais impactos da tecnologia na educação no período de pandemia de COVID-19.

Palavras-chave: Tecnologia. Importância. COVID. Educação.

\begin{abstract}
In December 2019, China notified the World Health Organization (WHO) about the epidemic of a virus similar to viral pneumonia in Wuhan province. In March 2020, a pandemic state was declared in all corners of the world due to the high infectivity of the new coronavirus, in order to mitigate its great contamination, authorities from all over the world, including in Brazil, chose to adopt maneuvers aimed at minimizing contagion, one of these maneuvers was social isolation, making traditional routines a little more flexible, as in the case of distance learning. Through a bibliographic survey, we sought to ascertain the main impacts of technology on education in the pandemic period of COVID-19.
\end{abstract}

Keywords: Technology. Importance. COVID. Education. 


\section{INTRODUÇÃO}

A infecção pelo novo coronavírus, colocou o mundo inteiro em estado de pandemia em março de 2020, alterando a qualidade de vida e rotina de toda a população. Atualmente, a covid19 tem se mostrado o maior desafio sanitário a nível mundial no século XXI. No Brasil, até o mês de abril de 2020, um mês após o alarme de pandemia, havia sido contabilizado 21 mil casos confirmados. A grande dificuldade passou a ser a escassez de conhecimento científico a respeito da mutação do vírus, sua velocidade de disseminação e progressão rápida e letal em populações vulneráveis, corroborando com a incerteza a respeito das melhores estratégias a serem endossadas para tratamento e prevenção (WERNECK e CARVALHO, 2020).

Nacionalmente, esse cenário é ainda mais grave pois existem poucas elucidações a respeito das características de transmissão se observado sob a ótica de desigualdade social, onde ainda é comum encontrar populações que vivem em condições precárias de habitação, resultando em situações de aglomeração. Muito foi discutido durante o último ano, sobre qual seria a melhor manobra para que o Brasil minimizasse o contágio e transmissão, se o isolamento vertical ou isolamento horizontal. Frente a isso, diversos debates a respeito de estratégias de isolamento foram levantados, levando em consideração que o isolamento seria a melhor medida para desacelerar a transmissão (COELHO et al., 2020).

De acordo com Werneck e Carvalho (2020) os governos estaduais buscaram colocar seus Estados em condição de "quarentena" durante vários períodos na tentativa de diminuir a curva epidemiológica da covid-19, com isso, diversas organizações passaram a se readaptarem com um novo cenário para continuarem a manter seus negócios em constante funcionamento, bem como o ensino e até a comunicação entre pessoas. É sabido que o desenvolvimento tecnológico está em constante evolução ano após ano, inovando não só em questão de alcance, mas também de funcionalidade de ferramentas.

A epidemia por covid-19 fez com a população brasileira entrasse em situação de extrema vulnerabilidade, com altíssima taxa de desemprego e cortes drásticos nas políticas sociais. Empresas passaram a reduzir gastos com instalações que acomodassem seus colaboradores, adotando o regime home office, que nada mais é do que realizar as atividades corporativas em sua residência utilizando apenas de rede, desktop e celulares. Além disso, a educação passou a observar a necessidade de continuar oferecendo ensino, para isso, foram elaborados planos de Ensino a Distância (EAD) para todas as classes da educação a fim de promover um ensino 
contínuo e minimizar os impactos do isolamento social longe das salas de aula (WERNECK e CARVALHO, 2020).

De acordo com Walker et al. (2020), para que essas medidas de contingência fossem possíveis, foi necessário inserção desse público nos ambientes virtuais, recorrendo ao acesso de aparelhos tecnológicos, redes e até mesmo à segurança da informação. A partir disso, além dessas ocasiões, procedimentos burocráticos que exigiam presença física em alguns estabelecimentos passaram a ser mais acessíveis, evitando filas, contato pessoal e até mesmo maior agilidade em questão de atendimento e resultado de entrega de demanda.

As últimas décadas, principalmente após a aprovação da Emenda Constitucional $\mathrm{n}^{\mathrm{o}} 95$, que implica na instituição radical do teto de gastos públicos e com políticas econômicas impostas pelo atual governo, que resulta em um crescente estrangulamento dos investimentos em saúde e pesquisa. É a partir desse cenário que passamos a observar que nos momentos de crise, que a sociedade passa a compreender a importância para um país de um sistema de ciência e tecnologia forte o bastante para contribuir com os avanços na saúde e nos seus sistemas a fim de garantir o acesso e direito à saúde (WERNECK e CARVALHO, 2020).

Esse artigo objetiva abordar os principais impactos da tecnologia na educação no período de pandemia de covid-19.

\section{A PANDEMIA DE COVID-19 E SUAS MUDANÇAS NA EDUCAÇÃO}

A Organização Mundial da Saúde (OMS), foi notificada em dezembro de 2019, pela China, a respeito de um surto de uma nova doença que era similar a uma pneumonia. Essa doença era oriunda da transmissão do novo coronavírus (SARS-COV-2) também conhecido como covid-19. Um mês mais tarde, em janeiro de 2020, novos casos dessa doença passaram a ser notificada em outros países além da China, com isso, a OMS passou a declarar emergência internacional em saúde pública. O primeiro caso registrado na América Latina foi em São Paulo, no Brasil, no dia 26 de fevereiro de 2020 (WU et al., 2020; BEZERRA et al., 2020; OMS, 2020). 


\subsection{O isolamento social}

Com a chegada do novo coronavírus no Brasil, uma série de condutas de controle e prevenção passaram a serem adotadas pelas autoridades sanitárias locais em diversas esferas administrativas, ou seja, pelos governos federal, estaduais e municipais. Essas condutas passaram a ser modificadas e adotadas de maneira variada de acordo com cada região, entretanto, ainda assim, a conduta mais adotada por essas autoridades foi a adoção de distanciamento social, também compreendido como isolamento social. Essa medida tem sido responsável pelo levantamento de diversas polêmicas Brasil a fora, visto que alguns governos tem se mostrado céticos quanto sua eficácia (BEZERRA et al., 2020).

De fato, a maioria dos tomadores dessa decisão passou a optar pelo incentivo dessa medida, adotando condutas estratégicas de controle de mobilidade populacional, intervindo no funcionamento de centros de ensinos, comércio não essencial, áreas de lazer, entre outros. Para Pires (2020), o resultado dessa conduta acarretou no apoio de grande parte dos brasileiros aderindo ao sistema de isolamento social, com o intuito de se prevenir da doença e contribuiu com a minimização dos contágios e consequente atenuação da curva epidemiológica no Brasil.

Entretanto, embora o isolamento social busque amenizar o contágio, grande parte da população sofreu com grandes impactos em suas vidas. Werneck e Carvalho (2020) acreditam que existe um vasto debate na mídia e no senso comum a respeito da queda na aderência ao isolamento social se comparado com uma população de renda maior, principalmente na questão de necessidade de locomoção ao trabalho, sugerindo que a população mais pobre, está associada às atividades essenciais, que exigem seu funcionamento, isso porque, a população com renda maior está associada às atividades que pararam de funcionar, sendo suas atividades, em muitas das vezes, acoplada em atividades remotas.

Um estudo realizado por Bezerra et al. (2020), evidenciou que cerca de $57 \%$ da população estudada (que corresponde ao total de 16.440 em diversos estados do país), adotaram o isolamento parcial, que diz respeito à mobilidade apenas para compras de medicamento e/ou alimentos. Ainda, tratando dessa população, 89\% dessas pessoas, acreditam que o isolamento contribui com a redução no número de infecções por covid-19. No que diz respeito aos fatores afetados em sua rotina, $39 \%$ dos voluntários acreditam que o principal aspecto afetado pelo isolamento, é o convívio social, enquanto $19 \%$ alegam que o isolamento não ocasionou nenhum impacto em suas rotinas.

Interface Tecnológica - v. 18 n. 1 (2021) 
Curiosamente, o mesmo estudo elucidado por Bezerra e seus colaboradores, evidenciou que $61 \%$ dos entrevistados, está disposto a permanecer o período que for necessário para enfrentar a disseminação do novo coronavírus, $20 \%$ conseguem se manter em isolamento até dois meses e apenas $16 \%$ não conseguem permanecer durante um mês inteiro nessa condição (BEZERRA et al., 2020).

\subsection{Os impactos da tecnologia no isolamento social}

É notório que mesmo em meio ao avanço tecnológico constante, que vem ganhando força a cada década, a educação, mesmo diante da modalidade EAD, é configurada como um setor que exige presença frequente não apenas sendo exigida em caráter legal, mas também por se tratar da melhor maneira de repassar os conteúdos programáticos para os alunos. Quanto à obrigatoriedade do ensino presencial por lei, de acordo com o inciso I do art 24 da Lei ${ }^{\circ}$ 9.394/1996 dos duzentos dias letivos:

A carga horária mínima anual será de oitocentas horas para o ensino fundamental e para o ensino médio, distribuídas por um mínimo de duzentos dias de efetivo trabalho escolar, excluído o tempo reservado aos exames finais, quando houver (BRASIL, 1996, p. 08),

Diante do cenário atual, o Governo Federal instituiu a medida provisória $n^{\circ} 934$ de $1^{\circ}$ de abril de 2020, na qual estabelece normas excepcionais para o cumprimento das regras previstas nos dispositivos legais, visando sua flexibilização. Portanto, as escolas de educação básica, bem como as instituições de ensino superior, podem distribuir a carga horário em um período diferente dos duzentos dias letivos previstos na legislação, desde que a carga horária mínima anual seja cumprida e respeitando as diretrizes a serem editadas pelo sistema educacional (PERA, 2020).

Entretanto, o estado de pandemia decorrente da contaminação pela covid-19, diversas esferas foram afetadas, ficando todas à mercê de um plano de contingência que realizasse uma reestruturação em seus sistemas, mesmo diante do seu tradicionalismo, com a educação não foi diferente. $\mathrm{O}$ sistema educacional passou a ser reestruturado de uma forma como na qual nunca tinha sido visto antes, em virtude do alto contágio pelo novo coronavírus, as autoridades nacionais adotaram uma série de manobras que evitassem o colapso do sistema de saúde em decorrência da incidência de contaminação, nesse passo, objetivou-se também, a manutenção 
da promoção da educação a fim de não prejudicar os alunos, como é assegurado segundo a Constituição Federal de 1988 que preconiza a educação como dever do Estado e direito de todos, portanto, a tecnologia passou a ser a ferramenta mais eficaz para manutenção contínua da educação até que o cenário de pandemia sofra modificações positivas (OLIVEIRA E SOUZA, 2020).

\subsection{A tecnologia como ferramenta educacional}

A partir do cenário mundialmente caótico, mudanças no cotidiano e a necessidade contínua de promover o ensino e minimizar os danos aos estudantes, a tecnologia passou a ser vista como única alternativa viável para auxiliar na promoção de ensino, mesmo que sua estrutura tradicional não tenha tanta necessidade no tocante à pandemia (LIMA, 2020). Sabemos que existem países que são grandes potências que utilizam tecnologia de ponta e uma sociedade com hábitos e preparos totalmente diferentes do Brasil, a principal dúvida que pareou e ainda insiste em questionar muitos estudiosos, de fato os brasileiros estão preparados para adotar uma rotina que dependa integralmente de todos os recursos tecnológicos disponíveis para atender à necessidade dos alunos, seguindo o conteúdo programático bem como a legislação educacional e consequentemente cumprir com aproveitamento os dias letivos obrigatórios?

Além disso, durante o desenvolvimento do presente artigo, passamos a observar diversas outras questões ligadas ao assunto, principalmente no que se refere ao acesso a essas tecnologias e seu uso como o porquê de um não preparo prévio para imersão no ambiente virtual de aprendizagem? E o preparo da equipe da tecnologia, estaria essa preparada para implantar sistemas, prestar suporte e integrar todas essas informações e atender toda essa necessidade? Como tratado nos tópicos anteriores, a pandemia obrigou que todas as esferas sociais se readaptassem à atualidade, criando estratégias e alternativas a fim de minimizar os impactos negativos decorrente desse evento.

Na última década, instituições educacionais passaram a incluir em suas grades, matérias EAD que visavam o ensino e aproveitando dessa disciplina, com o passar dos anos, com o desenvolvimento da sociedade e acúmulo de rotinas cansativas, diversos cursos dos ensinos técnico e superior, passaram a oferecer cursos integralmente pela modalidade EAD a fim de oferecer oportunidades àqueles que não dispunham de conciliação de tempo nas suas rotinas, flexibilizando seu ensino, proporcionando que seu acesso ao curso fosse realizado de acordo 
com sua disponibilidade de horário, desde que entregue suas atividades e avaliações, dentro de período estabelecido pela instituição para que o aluno fosse avaliado. De acordo com o art $1^{\text {ao }}$ do Decreto n ${ }^{\circ}$ 9.057/2017, entende-se por EAD:

A modalidade educacional na qual a mediação didático-pedagógica nos processos de ensino e aprendizagem ocorra com a utilização de meios e tecnologias de informação e comunicação, com pessoal qualificado, com políticas de acesso, com acompanhamento e avaliação compatíveis, entre outros, e desenvolva atividades educativas por estudantes e profissionais da educação que estejam em lugares e tempos diversos (BRASIL, 2017, p. 03).

A partir desse contexto, Kenski (2010) acredita que a EAD por meio de todo seu desenvolvimento e benefícios observados no decorrer dos anos, passou a ser tida como alternativa considerável para contribuir com a entrega da demanda educacional em vista das medidas de contenção de contaminação do novo coronavírus, por meio do isolamento social, visto que durante esse tempo, possibilitou o acesso remoto à educação de maneira eficiente.

Quanto ao aproveitamento e conteúdo, a questão desafiadora que tange o processo de pandemia e o uso da tecnologia na educação, é quanto ao sistema de avaliação a aproveitamento, é sabido que o intuito da tecnologia é reduzir processos, economizar tempo e gerar comodidade, a partir disso questiona-se: se no método presencial aplicado tradicionalmente, chamado de prova, o educador conclui através de sua análise diante dos resultados do aluno com base no que foi aplicado em sala de aula, se o acadêmico concluiu o período com rendimento ou não, durante utilização integral de ensino hibrido, os resultados e conclusões avaliativas podem ser a mesma que no ensino presencial?

Certamente a resposta para a questão anterior seria sim, afinal, devemos que considerar que o mundo pós pandemia não será o mesmo mundo anterior à pandemia, muito pelo contrário. Devemos considerar que processos serão reduzidos, não em questão de conteúdo de ensino, mas nas questões avaliativas, não exigindo - muito provavelmente - a presença de professor presencial para que o aluno de fato aprenda ou seja avaliado. De maneira didática, exemplifiquemos essa hipótese a partir da situação onde o professor dispõe de um determinado período para esclarecimento de dúvidas após conteúdo aplicado, caso sua disponibilidade, bem como a do aluno, seja apenas através de um ambiente virtual, seu esclarecimento e compreensão do aluno seria menos eficaz do que um esclarecimento presencial? 
Obviamente que a relação professor-aluno sempre será um elo que resultará na educação do estudante e que essa relação é imprescindível no processo de aprendizagem, o que muito se entende, é durante o período de EAD essa relação seja fragilizada, o que é inverídico, visto que essa modalidade de ensino permite que o aluno se comunique com seu educador bem como o educador com os alunos. É a partir da hipótese de Caldeira (2013), que compreendemos que a relação professor-aluno é fundamental pois é através dessa que o educador poderá resolver muitos problemas de aprendizagem, visto que esse resultado pode estar associado a sua metodologia de ensino, que em muitas das vezes é individualizada se tratando de professor para professor, na qual resulta em processo de avaliação marcante, definindo essa metodologia como característica marcante de cada docente.

Quanto ao que diz respeito à metodologia de ensino, Oliveira e Souza (2020) acredita que o processo de avaliação utilizado pelo docente não pode ter dissociação da metodologia de ensino para que de fato seja concretizada a aprendizagem. O que muito pode ser afetado são as questões afetivas, segundo Caldeira (2013), as manifestações de afeto em muitas das ocasiões são observadas na relação professor-estudante, que podem atuar de maneira favorável seja para o aprendizado do estudante bem como para evolução do docente em sua carreira.

Entretanto, Belotti e Faria (2010), afirmam que estudos tem enfatizado a grande necessidade do docente ter a capacidade de realizar uma reflexão a respeito da sua prática, direcionando-a de acordo com a realidade que se vive, focando nos interesses e nas necessidades dos acadêmicos, focando na busca de novas rotas, contribuindo para que a aprendizagem seja um desafio estimulador para cada um. Por fim, uso as palavras de Schon (1997, p 21.) para corroborar com o que foi apresentado durante esse artigo: "existem situações conflitantes, desafiantes, que a aplicação de técnicas convencionais, simplesmente não resolve problemas".

\section{PROCEDIMENTOS METODOLÓGICOS}

Para desenvolvimento desse artigo, foi realizado uma revisão de literatura, nesse sentido, Appolinário (2009) afirma que esse tipo de estudo objetiva assegurar e propiciar maior familiaridade com o problema, a fim de transformá-lo de modo visível ou de elaborar hipóteses. Seu planejamento é, portanto, bastante flexível, de modo que possibilite as considerações dos mais variados aspectos relativos ao fato estudado. Os conteúdos bibliográficos foram extraídos 
a partir das bases de pesquisa MedLine (Medical Literature Analysis and Retrievel System Online), Google Scholar e SciELO (Scientific Electronic Library Online) através dos seguintes descritores: Tecnologia. Importância. Covid. Educação.

\subsection{Delineamento da Pesquisa}

Foram filtradas 255 referências através dos descritores, utilizando como filtro os últimos 10 anos, nos idiomas português e inglês. Desse total, 120 foram excluídos pois se tratavam de artigos repetidos; 56 não correspondiam com a temática proposta; 52 não possuíam conteúdo na íntegra e 7 possuíam publicação superior a 10 anos. Esse artigo utilizou 20 referências para desenvolvimento e tratativa do assunto e consequente resultado e conclusão a respeito dos objetivos sugeridos.

\section{CONSIDERAÇÕES FINAIS}

É notório que mundialmente, a covid-19 exigiu mudanças bruscas em todos os cantos do mundo a fim de conter a disseminação do vírus, para isso, rotinas comuns passaram a ser vistas como grandes desafios a serem enfrentados, fazendo com que muitos, se não todos, passassem por reestruturações que visem sua continuidade. A educação é um dever do Estado e direito de todos e desde sempre foi motivo de grandes discussões a respeito do seu desenvolvimento e promoção. Nos últimos anos, em decorrência do constante avanço tecnológico e em busca de oferecer comodidade e aprendizagem de maneira remota, em decorrência da rotina cansativa e não conciliação de rotinas, a educação a distância passou a ser instituída para algumas matérias de determinados cursos superiores, mais tarde, passou a englobar grades curriculares de diversos cursos integralmente de maneira digital.

Diversos questionamentos passaram a ser levantados durante o período que antecedia a decisão de direcionar a aprendizagem para ambientes virtuais para todas as formas de ensino, seja básica, seja superior, a respeito da eficácia e aprendizagem do educando com esse novo sistema de ensino. A partir do desenvolvimento desse artigo e objetivos propostos, podemos concluir que a tecnologia tem sido grande aliada na esfera educacional durante o período de isolamento social, diminuindo a distância entre o docente e a sala de aula através dos ambientes virtuais projetados para realização de vídeo aulas, atividades online, avaliações, etc. A 
tecnologia é ferramenta útil no século atual, reduzindo processos, encurtando rotinas e aproximando pessoas, entretanto, é necessário que estudos e metodologias sejam elucidadas com foco na educação para que de fato a sociedade esteja apta a adotar essa modalidade de ensino mesmo no período pós pandemia, corroborando ainda mais com a hipótese de que a tecnologia pode ser considerada sim, um instrumento de educação e aprendizagem.

\section{REFERÊNCIAS}

Appolinário, F. Dicionário de metodologia científica: um guia para a produção do conhecimento científico. São Paulo, Atlas, 2009.

Bezerra, A.C.V.; Silva, C.E.M.; Soares, F.R.G.; Silva, J.A.M. Fatores associados ao comportamento da população durante o isolamento social na pandemia de COVID-19. Ciênc. saúde coletiva 25 (suppl 1) Jun 2020. Disponível em https://doi.org/10.1590/141381232020256.1.10792020. Acessado em 03 abr. 2021.

Belotti, S.H.A.; Faria, M.A. "Relação professor/aluno". Revista Eletrônica Saberes da Educação, vol. 1, n. 1, 2010.

Brasil. Constituição da República Federativa do Brasil. Brasília: Planalto, 1988 Disponível em: http://planalto.gov.br. Acessado em 03 abr. 2021.

Brasil. Lei n. 9.394, de 20 de dezembro, 1996. Disponível em: http://planalto.gov.br. Acessado em 03 abr. 2021.

Brasil. Decreto n. 9.057, de 25 de maio, 2017. Disponível em: http://planalto.gov.br. Acessado em 03 abr. 2021.

Brasil. Medida Provisória n. 934, de 1 de abril, 2020. Disponível em: http://planalto.gov.br. Acessado em 03 abr. 2021.

Caldeira, J.S. "Relação Professor-Aluno: uma reflexão sobre a importância da afetividade no processo de ensino aprendizagem". Anais do XI Congresso Nacional de Educação (XI EDUCERE) / II Seminário Internacional de Representações Sociais, Subjetividade e Educação (II SIRSSE) / do IV Seminário Internacional sobre Profissionalização Docente (IV SIPD). Curitiba: PUC-PR, 2013. 
Coelho, F.C et al. Assessing the potential impact of COVID-19 in Brazil: mobility, morbidity and the burden on the health care system. medRxiv 2020; 26 mar. Disponível em: https://www.medrxiv.org/content/10.1101/2020.03.19.20039131v2. Acessado em 03 abr. 2021.

Kenski, V.M. "Avaliação e acompanhamento da aprendizagem em ambientes virtuais a distância”. In: Mill, D. R. S.; Pimentel, N. M. (orgs.). Educação a distância: desafios contemporâneos. São Carlos: EdUFSCar, 2010.

Lima, J.D. O distanciamento social como redutor de contaminações. Nexo [17/03/2020]. Disponível em: http://nexojornal.com.br. Acessado em 03 abr. 2021.

Oliveira, H.V.; Souza, F.S. Do conteúdo programático ao sistema de avaliação: reflexões educacionais em tempos de pandemia (COVID-19). Boletim de Conjuntura (BOCA). ano II, vol. 2, n. 5, Boa Vista, 2020

Organização Mundial da Saúde (OMS). Rolling updates on coronavirus disease (COVID19) 2020. Geneva: WHO; 2020.2 Disponível em: https://www.who.int/emergencies/diseases/novel-coronavirus 2019/events-as-they-happen. $\begin{array}{lllll}\text { Acessado } & \text { em } & 03 & \text { abr. } & 2021 .\end{array}$

Pera, G. Ano letivo poderá ter menos de 200 dias. Portal do MEC [01/04/2020]. Disponível em: <http://portal.mec.gov.br> (Acesso em 03 abr 2021).

Pires, R.R.C. Os efeitos sobre grupos sociais e territórios vulnerabilizados das medidas de enfrentamento à crise sanitária da covid-19: propostas para o aperfeiçoamento da ação pública: Nota Técnica Brasília: IPEA; 2020. Disponível em: http://www.ipea.gov.br/portal/index.php?option=com_alphacontent\&view=alphacontent\&Ite mid=357. Acessado em 03 abr. 2021.

Schon, D. Os professores e sua formação. Lisboa: Publicações Dom Quixote, 1997.

Walker, P. et al. Report 12: The global impact of COVID-19 and strategies for mitigation and suppression. Disponível em: http://spiral.imperial.ac.uk/handle/10044/1/77735. Acessado em 03 abr. 2021.

Werneck, G.L.; Carvalho, M.S. A pandemia de COVID-19 no Brasil: crônica de uma crise sanitária anunciada. Cad. Saúde Pública 36 (5) 8 Maio 2020. Disponível em https://doi.org/10.1590/0102-311X00068820. Acessado em 03 abr. 2021. 
$\mathrm{Wu}, \mathrm{F}$. et al. A new coronavirus associated with human respiratory disease in China. Nature 2020; 579(7798):265-269. 